\title{
EQCM Behavior of Copper Anodes in Alkaline Medium and Characterization of the Electrocatalysis of Ethanol Oxidation by $\mathrm{Cu}$ (III)
}

\author{
Thiago R. L. C. Paixão, Eduardo A. Ponzio, Roberto M. Torresi and Mauro Bertotti* \\ Instituto de Química, Universidade de São Paulo, 05508-900 São Paulo - SP, Brazil
}

\begin{abstract}
A oxidação anódica de eletrodos de cobre em meio alcalino foi investigada utilizando-se voltametria, cronoamperometria, medidas de impedância eletroacústica e microbalança eletroquímica de cristal de quartzo (MECQ). Os experimentos foram realizados em soluções de $\mathrm{NaOH}$ na faixa de concentração de 0,1 a $3,0 \mathrm{~mol} \mathrm{~L}^{-1}$. A formação de espécies solúveis e insolúveis como $\mathrm{Cu}(\mathrm{OH})_{4}{ }^{2-}$ and $\mathrm{Cu}_{2} \mathrm{O}$ durante o processo de dissolução eletroquímica foi caracterizada por estudos potenciodinâmicos e pela análise das relações entre massa e carga. Por outro lado, os resultados obtidos utilizando a MECQ não foram satisfatórios para confirmar a natureza das espécies de cobre propostas na literatura como $\mathrm{CuO}$ e $\mathrm{Cu}(\mathrm{OH})_{2}$, visto que há mudanças viscoelásticas do filme eletrodepositado sobre o cristal de quartzo. A participação de espécies solúveis de $\mathrm{Cu}(\mathrm{III})$ no processo eletrocatalítico de oxidação do etanol foi caracterizada pelas medidas obtidas com a MECQ. Com estes dados foi possível propor um modelo para explicar o processo eletródico envolvendo a oxidação do etanol na superfície de cobre.
\end{abstract}

The anodic oxidation of copper electrodes in alkaline solutions was investigated by using voltammetry, chronoamperometry, impedance measurements and the electrochemical quartz crystal microbalance (EQCM). Experiments were carried out in $\mathrm{NaOH}$ solutions in the 0.1 to $3.0 \mathrm{~mol} \mathrm{~L}^{-1}$ concentration range. The formation of soluble and insoluble species such as $\mathrm{Cu}(\mathrm{OH})_{4}{ }^{2-}$ and $\mathrm{Cu}_{2} \mathrm{O}$ during the electrodic dissolution of copper anodes was characterized by analyzing potentiodynamic mass responses and the relationship between mass changes and charge. On the other hand, EQCM data were not effective to confirm the nature of other copper species proposed in literature named as $\mathrm{CuO}$ and $\mathrm{Cu}(\mathrm{OH})_{2}$ because of viscoelastic changes in the film layer electrodeposited onto the quartz crystal. The participation of a $\mathrm{Cu}$ (III) soluble species in the electrocatalytic oxidation of ethanol was proved by EQCM measurements, data providing valuable information on the mechanism of the electrode process and formation of a $\mathrm{Cu}(\mathrm{II})$ insoluble species from the reaction of $\mathrm{Cu}(\mathrm{III})$ with ethanol.

Keywords: copper electrode, electrochemical quartz crystal microbalance, ethanol oxidation

\section{Introduction}

For active metallic electrodes such as copper, the electrodic process in alkaline medium involves the formation of oxides of higher oxidative states, i.e., $\mathrm{Cu}(\mathrm{III}),{ }^{1}$ one of them being proposed to behave as a redox mediator in electrocatalytic processes. ${ }^{2-5}$ Accordingly, the anodic oxidation of some compounds such as carbohydrates and small organic molecules (for instance, ethanol) is facilitated at copper surfaces, analytical methods with high sensitivity being developed..$^{3-5}$ Also, stable long-term detection in flow systems is feasible, whereas pulsed potential waveforms are required to overcome fouling problems at other electrodic

*e-mail: mbertott@iq.usp.br surfaces such as glassy carbon, platinum and gold. ${ }^{6,7}$ Because of these distinctive features, copper and copper-based electrodes have received considerable attention as they can be used as amperometric detectors in liquid chromatography, ${ }^{8}$ capillary electrophoresis ${ }^{9}$ and FIA systems. ${ }^{3,10,11}$

Electrocatalytic reactions involving the anodic oxidation of substrates at copper surfaces have been largely investigated and a mechanism based on the mediation by a $\mathrm{Cu}$ (III) species is the more accepted. ${ }^{2}$ By using rotating ring-disc voltammetry, we have confirmed previous studies that suggest the formation of a free-soluble $\mathrm{Cu}$ (III) species by polarizing copper anodes in $\mathrm{NaOH}$ solutions at relatively large positive potentials. ${ }^{4}$ Addition of ethanol to the working solution led to the consumption of the $\mathrm{Cu}$ (III) species, with the concurrent enhancement of the 
anodic signal owing to the electrocatalytic process. Analytical applications have been performed by using copper detectors for several compounds at both stationary and flow conditions. , $^{3,8-12}$

Some attempts to understand the pathway of the formation of this electroactivelly $\mathrm{Cu}$ (III) species have involved the use of both electrochemical and surface analytical techniques. ${ }^{13-15}$ Surprisingly, only a few reports on the use of the electrochemical quartz crystal microbalance (EQCM) to investigate electrodic processes at copper surfaces have been found in literature, studies being performed in moderately alkaline solutions $\left(\mathrm{NaHCO}_{3}+\mathrm{Na}_{2} \mathrm{CO}_{3},{ }^{16}\right.$ borate buffers ${ }^{17}$ ) and in $0.01 \mathrm{~mol} \mathrm{~L}^{-1} \mathrm{NaOH}$ solution in the negative potential region. ${ }^{18}$ Because the corrosion of copper anodes in alkaline medium involves the formation of oxides, hydroxides and soluble species, the use of EQCM is certainly attractive. Accordingly, the aim of this work is to examine once again the electrochemical behavior of copper in $\mathrm{NaOH}$ solutions by comparing current information with mass changes as the potential is scanned in the region of oxides formation. Furthermore, results of some experiments to shed some light on the mechanism of the electrooxidation of ethanol at this electrodic material are also shown.

\section{Experimental}

Reagents

Solutions were prepared with deionized water processed through a water purification system (Nanopure Infinity, Barnstead). Analytical grade chemicals were used as received: sodium hydroxide (Dinâmica; São Paulo, Brazil), absolute ethanol (Merck; Darmstadt, Germany) and copper sulfate (Merck; Darmstadt, Germany).

\section{Instrumentation}

Measurements in all the experiments were performed in a conventional three-electrode electrochemical cell. The solution volume was $20 \mathrm{~mL}$ and the design of the electrochemical cell has been described elsewhere. ${ }^{19}$ The working electrode was a $6 \mathrm{MHz}$ AT-cut piezoelectric quartz crystal with diameter of $25 \mathrm{~mm}$ and a piezo active electrode area of $0.31 \mathrm{~cm}^{2}$. Both electrode sides were previously evaporated with gold onto a chromium layer in order to improve adherence of gold onto the quartz substrate. Frequency resonance shift was transformed in mass change using the Sauerbrey equation ${ }^{20}(\Delta \mathrm{f}=-\mathrm{K}$ $\Delta \mathrm{m})$ where the integral sensitivity constant, $\mathrm{K}\left(6.5 \times 10^{7}\right.$ $\mathrm{g} \mathrm{cm}^{-2} \mathrm{~Hz}^{-1}$ ), was initially obtained by electrodeposition from a copper sulfate solution $\left(0.5 \mathrm{~mol} \mathrm{~L}^{-1}\right)$ in an acidic medium $\left(\mathrm{H}_{2} \mathrm{SO}_{4}, \mathrm{pH}=1\right)$, and this value is in agreement with that obtained when the calibration was carried out by silver electrodeposition. ${ }^{21}$ This $\mathrm{Cu}$ (II) solution was also used to obtain the copper electrodes used in all experiments, the electrodeposition of copper being performed at $\mathrm{E}=-0.1 \mathrm{~V}$ for 30 minutes. The verification of the copper deposition was accomplished by measuring the charge/mass ratio $\left(3.31 \times 10^{-4} \mathrm{~g} \mathrm{C}^{-1}\right)$, that corresponds to a molar mass of $63.9 \mathrm{~g} \mathrm{~mol}^{-1}$. This value is in agreement with the theoretical one $\left(63.54 \mathrm{~g} \mathrm{~mol}^{-1}\right)$, indicating the efficacy of the copper electrodeposition. This procedure was carried out before each electrochemical experiment, previous copper layers being removed by immersing the electrode in a $10 \%(\mathrm{v} / \mathrm{v}) \mathrm{HNO}_{3}$ solution. $\mathrm{A} \mathrm{Ag} / \mathrm{AgCl}$ (saturated $\mathrm{KCl}$ ) and a platinum wire were used as reference and auxiliary electrodes, respectively. Electrochemical experiments were carried out with a model PG 3901 Omnimeta potentiogalvanostat. Frequency shifts during the potential scan were measured by using a Stardford Research Systems analyzer, model SR 620, connected to a microcomputer for data acquisition. Electroacoustic impedance measurements (EAI) experiments were carried out with a HP 4194A impedance analyzer, with working frequency range of $5 \mathrm{~Hz}$ to $13 \mathrm{MHz}$. In these experiments, an alternating voltage $( \pm 0.3 \mathrm{~V})$ of a specific frequency was applied to the quartz-crystal. The phase and amplitude of the ac current were measured and used to calculate various parameters related to the mechanical impedance of the crystal. The frequency range typically scanned in these experiments was $\pm 30 \mathrm{kHz}$ around the fundamental resonance frequency, $6 \mathrm{MHz}$, using frequency steps between 10 and $50 \mathrm{~Hz}$, depending on the width of the frequency resonance. Previous reports have detailed the dependence of the mechanical impedance of quartzcrystals on both film and solution properties. ${ }^{22,23}$ Using locally built electrochemical cells and instrumentation, it is possible to make such measurements while one face of the quartz-crystal is in an electrolytic solution and under potential control, allowing the in situ investigation of the mechanical impedance of the various copper oxide species electrodeposited onto the electrode surface.

\section{Results and Discussion}

\section{Electrochemical behavior of copper electrodes in $\mathrm{NaOH}$ supporting electrolyte}

Experiments in $1 \mathrm{~mol} \mathrm{~L}^{-1} \mathrm{NaOH}$ solutions. Copper surfaces are free of oxides at potentials more negative than $c a$. $-0.5 \mathrm{~V}$ vs $\mathrm{Ag} / \mathrm{AgCl}$ in $\mathrm{NaOH}$ solutions at conventional concentrations $\left(0.1\right.$ to $\left.1.0 \mathrm{~mol} \mathrm{~L}^{-1}\right)$. By scanning the 
potential to more positive values, layers of oxides, hydroxides and free-soluble copper species in the I, II and III oxidation states are generated. Furthermore, interconvertion between different copper species, ageing phenomena, porosity of the films, formation of passivating layers and nature of mass transport of hydroxide ions to the electrode surface and their local concentration are all aspects that influence the current response in electrochemical experiments carried out with copper electrodes in alkaline medium. ${ }^{24-26}$ Literature ${ }^{27}$ on this subject covers both kinetics and structural aspects, even though some apparent discrepancy still remains, especially in the case of the participation of a $\mathrm{Cu}$ (III) species in electrocatalytic processes.

In order to exemplify this complex behavior, Figure 1 shows a typical voltammetric curve obtained by sweeping the potential from a region where the copper surface is free of oxides $(-0.9 \mathrm{~V})$ to the positive potential region. By measuring simultaneously frequency shifts as the potential is scanned, both $\mathrm{d} \Delta \mathrm{f} / \mathrm{dt}$ and $\Delta \mathrm{f}$ can be calculated as shown in Figure 1. Mass change values can be determined by using the Sauerbrey equation ${ }^{20}$ as mentioned in the experimental section. With values of $\Delta \mathrm{m}$ and charge obtained from the cyclic voltammetry, information on the chemical composition of the species formed on the surface of the electrode can be acquired by using the charge, mass change and the Faraday law. Notwithstanding, it is well known that quartz-crystal frequency changes can be

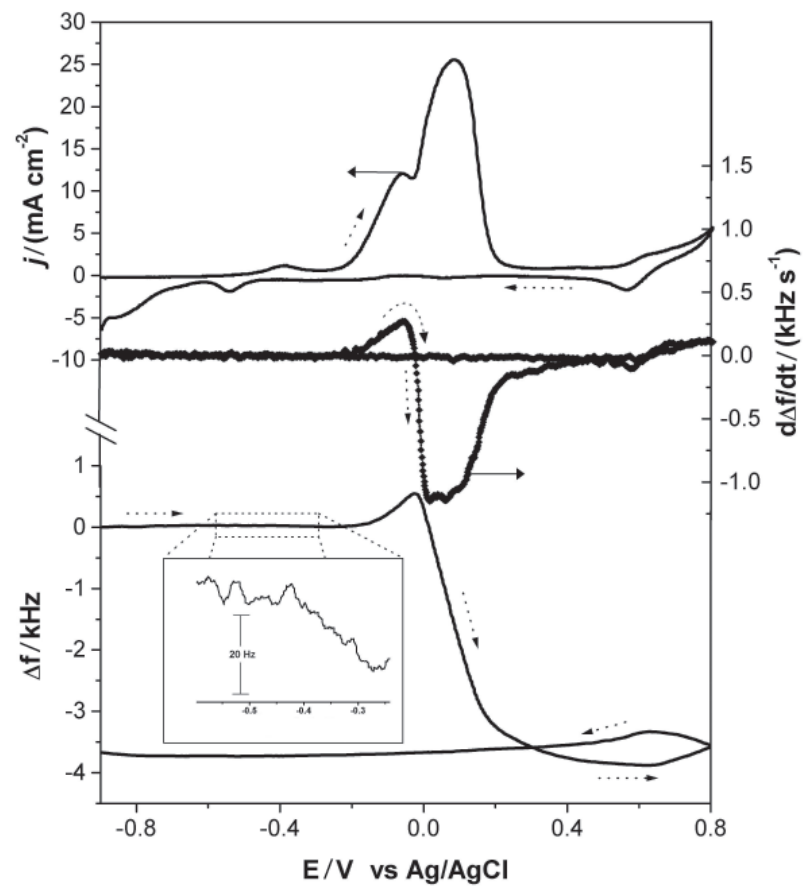

Figure 1. Cyclic voltammetry (-), $\Delta \mathrm{f}(-)$ and $\mathrm{d} \Delta \mathrm{f} / \mathrm{dt}(-\bullet)$ vs potential plots for a copper electrodeposited quartz-crystal during the potential scan in $1 \mathrm{~mol} \mathrm{~L}^{-1} \mathrm{NaOH}$ supporting electrolyte. Scan rate: $50 \mathrm{mV} \mathrm{s}^{-1}$. influenced by redox induced changes in the viscoelastic properties of the films being investigated..$^{23}$ Thus, in order to confirm that the Sauerbrey relationship can be used to calculate mass changes from the frequency changes observed during EQCM experiments, it is important to confirm that the thin films being investigated behave rigidly. With this in mind, EAI measurements were made for both a bare quartz-crystal electrode and a quartz-crystal electrode after electrodeposition of a thin copper film. These measurements were performed in all of the various electrolyte systems that were investigated, open circuit conditions being used for both bare and copper electrodeposited electrodes. In the case of the redox transformation onto the copper film, EAI experiments were carried out at open circuit condition after applying a potentiodynamic perturbation in order to produce the redox change. The potential-time protocol is shown in Figure 3 (insert).

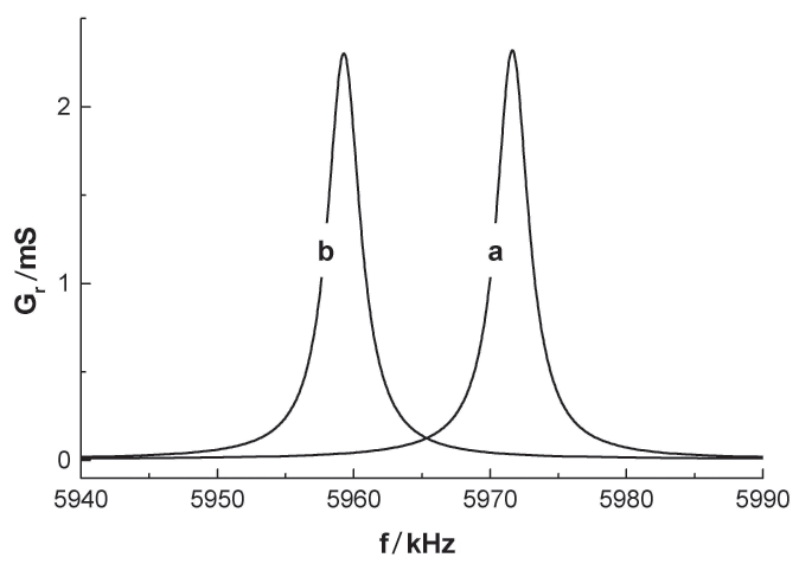

Figure 2. Conductance spectra of a quartz-crystal (a) and a quartz-crystal after copper electrodeposition (b) in a $0.5 \mathrm{~mol} \mathrm{~L}^{-1}$ copper sulfate solution (deposition solution). Scan rate: $50 \mathrm{mV} \mathrm{s}^{-1}$.

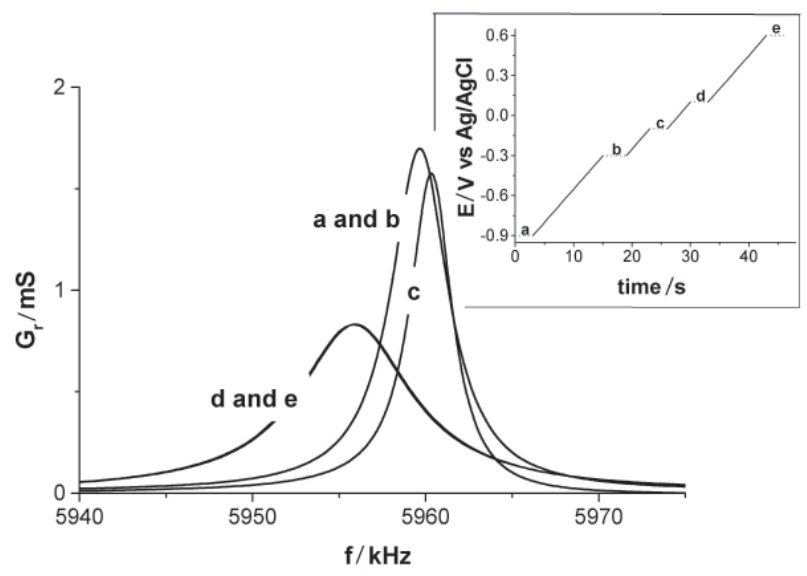

Figure 3. Conductance spectra of a copper electrodeposited quartz-crystal before (a) and after polarization until -0.3 (b), - 0.1 (c), 0.1 (d) and 0.6 $\mathrm{V}$ (e) vs $\mathrm{Ag} / \mathrm{AgCl}$, in $1 \mathrm{~mol} \mathrm{~L}^{-1} \mathrm{NaOH}$ solution. Scan rate: $50 \mathrm{mV} \mathrm{s}^{-1}$. Dashed lines (- - ) represent the impedance measurements, which were performed at open-circuit conditions. 
Figure 2 shows conductance spectra for a quartzcrystal electrode in $0.5 \mathrm{~mol} \mathrm{~L}^{-1}$ copper sulfate solution $(\mathrm{pH}=1)$ before (curve a) and after electrodeposition of a copper layer (curve b). Full width values at half maximum of the conductance peaks $\left(\Delta \mathrm{f}_{\text {fwhm }}\right)$ are slightly different for both electrodes $(2960 \mathrm{~Hz}$ for bare and 2840 $\mathrm{Hz}$ for electrodeposited copper). The frequency maximum $\left(f_{o}\right)$ of the conductance plot suffers a diminution of approximately $12 \mathrm{kHz}$ associated with the mass increase produced by the copper electrodeposition. The quality factor is often a useful measure of the loss of mechanical energy from the vibrating crystal to the film or solution. ${ }^{23}$ It can be defined as $Q=\mathrm{f}_{\mathrm{o}} / \Delta \mathrm{f}_{\mathrm{fwhm}}$ and $\mathrm{Q}$ values are virtually the same for both electrodes $(\sim$ 2050). For crystals of the design used in this work, quality factors in air can approach $10^{4}$. The relatively low values observed for the quality factor in all of these solutions is attributed to the viscosity. The value of conductance at the peak maximum, $\mathrm{G}_{\max }$, was monitored for both electrodes. Differences of less than $1 \%$ were observed. Since $G_{\max }$ is inversely proportional to the film viscosity, ${ }^{22,23}$ it is possible to conclude that the metallic copper deposit behaves as acoustically rigid. Thus, these results validate the use of the Sauerbrey equation for mass calculations based on EQCM frequency data in these conditions.

Figure 3 shows the conductance spectra of electrodeposited copper in $\mathrm{NaOH}$ solution at different redox states according to the potential-time protocol shown in the insert. Curve a exhibits the conductance spectrum at open circuit conditions before electrochemical treatment in this solution. If this spectrum is compared with that of Figure 2 (curve b), there is an increase in $f_{o}$ and $\Delta f_{\text {fwhm }}$ but a diminution of Q ( 1500) and these changes can be assigned to a change in the viscosity of the electrolyte solution (from copper sulfate to $\mathrm{NaOH}$ ). As indicated in Figure 3 (insert), a potential sweep starting at $-0.9 \mathrm{~V}$ until $-0.3 \mathrm{~V}$ at $50 \mathrm{mV} \mathrm{s}^{-1}$ was applied and after that the circuit was opened, the conductance spectrum being then registered (curve b). Both spectra (a and b) are similar indicating that there are no viscoelastic changes after polarization of the electrode at this potential value. Then, a potential sweep from $-0.3 \mathrm{~V}$ to $-0.1 \mathrm{~V}$ at $50 \mathrm{mVs}^{-1}$ was applied and the conductance spectrum was taken after this treatment at open circuit condition (curve c). Comparing with curve $b$, there is an increase of $f_{0}$ in $\sim 570 \mathrm{~Hz}$, showing a mass diminution associated with an electrodic dissolution process. The $\mathrm{Q}$ value was $\sim 2100$ and there is a diminution of $\sim 5 \%$ of $\mathrm{G}_{\max }$; so, it is possible to conclude that in this potential region, the Sauerbrey equation can be used to transform frequency shifts in mass change. After this experiment, the potential was swept until $0.1 \mathrm{~V}$ and the circuit was opened. Curve d shows the conductance spectrum obtained in this condition. There is a diminution of $f_{o}$ and also a diminution of $\mathrm{Q}(\sim 756)$ and $\mathrm{G}_{\max }(0.84 \mathrm{mS})$, clearly indicating a mass increase. However, the large decrease of $\mathrm{Q}$ and $\mathrm{G}_{\max }$ compared with curve $\mathrm{c}$ suggests that important viscoelastic and/or surface roughness changes are provoked owing to the formation of copper oxides and/or hydroxides. Therefore, at these experimental conditions the relationship between frequency changes and electrode mass is not valid and no conclusions on the extent of reactions occurring at this potential value can be done. Finally, the potential was swept until $0.6 \mathrm{~V}$ and the conductance spectrum was again obtained at open circuit conditions. As can be seen in Figure 3 (curve e), the conductance spectrum is similar to that of curve $\mathrm{d}$, showing that during this electrochemical treatment no significant changes in $\mathrm{Q}$ and $\mathrm{G}_{\max }$ occur. Hence, in this region the Sauerbrey equation can be again used for mass calculations.

During the positive sweep toward positive potentials, three main anodic processes should be discussed in Figure 1: the oxidation of $\mathrm{Cu}$ to $\mathrm{Cu}(\mathrm{I})$ and $\mathrm{Cu}(\mathrm{II})$ at around $-0.4 \mathrm{~V}$ and $0 \mathrm{~V}$, respectively, and the further generation of $\mathrm{Cu}(\mathrm{III})$ at more positive potentials ( $\mathrm{ca} .0 .6$ V). More detailed information on these electrodic reactions follows below:

i)Peak at around $-0.4 \mathrm{~V}$ : this current peak is attributed to a $\mathrm{Cu} / \mathrm{Cu}(\mathrm{I})$ redox couple. In the literature ${ }^{24}$ this process has been ascribed as

$$
2 \mathrm{Cu}+2 \mathrm{OH}^{-} \rightleftharpoons \mathrm{Cu}_{2} \mathrm{O}+\mathrm{H}_{2} \mathrm{O}+2 \mathrm{e}^{-}
$$

The insert in Figure 1 shows a very small decrease in frequency, i.e. increase in mass, in this potential region, compared with the process at more positive potentials. By calculating the theoretical $\Delta \mathrm{m} / \mathrm{q}$ ratio (using equation 1), a value of $8.2 \times 10^{-5} \mathrm{~g} \mathrm{C}^{-1}$ is obtained. This result is close to that obtained from Figure 1 with an experimental value of $9.0 \times 10^{-5} \mathrm{~g} \mathrm{C}^{-1}$, confirming the formation of $\mathrm{Cu}_{2} \mathrm{O}$.

ii) Peaks at around $O V$ : in this potential region, two anodic processes are observed with $\mathrm{E}_{\mathrm{pal}}=-0.05 \mathrm{~V}$ and $\mathrm{E}_{\mathrm{pa} 2}=0.10 \mathrm{~V} \cdot \Delta \mathrm{f} v s$. potential curve in Figure 1 shows an initial small increase in frequency (mass diminution) and then a remarkable frequency decrease (mass increase) at potentials corresponding to a second process. The dissolution of the copper electrode in alkaline supporting electrolyte has been ascribed as

$\mathrm{Cu}+4 \mathrm{OH}^{-} \rightleftharpoons \mathrm{Cu}(\mathrm{OH})_{4}{ }^{2-}+2 \mathrm{e}^{-}$ 
leading to a theoretical $\Delta \mathrm{m} / \mathrm{q}=-3.29 \times 10^{-4} \mathrm{~g} \mathrm{C}^{-1}$. By analysis of the data at the foot of the anodic wave (in the range -0.2 to $-0.1 \mathrm{~V}$, where the Sauerbrey equation may be used), $\Delta \mathrm{m} / \mathrm{q}$ was found to be $-3.21 \times 10^{-4} \mathrm{~g} \mathrm{C}^{-1}$, confirming the nature of the free-soluble $\mathrm{Cu}$ (II) generated at this experimental condition. The increase in the electrode mass at slightly more positive potentials is caused by the deposition of a mixture of copper(II) oxide $\left(\mathrm{CuO}, \mathrm{K}_{\mathrm{s}}=\right.$ $\left.7.8 \times 10^{-21}\right)^{27}$ or hydroxide $\left(\mathrm{Cu}(\mathrm{OH})_{2}, \mathrm{~K}_{\mathrm{s}}=1.6 \times 10^{-19}\right){ }^{27}$ This is a consequence of both the increase of the extent of the copper oxidation and the reduction of the local concentration of hydroxide ions at the interfacial region, as suggested in a previous work. ${ }^{28}$

The $\mathrm{d} \Delta \mathrm{f} / \mathrm{dt} v \boldsymbol{s}$. potential curve presented in Figure 1 also demonstrates the relationship between the oxidation processes with the decrease and increase in frequency. Positive values of $\mathrm{d} \Delta \mathrm{f} / \mathrm{dt}$ are observed in the potential region that corresponds to the dissolution process and this a clear indication of formation of soluble species. For more positive potentials, $\mathrm{d} \Delta \mathrm{f} / \mathrm{dt}$ changes sign going to negative values, indicating a modification of the redox reaction towards the formation of insoluble species as described in equations 3 and 4 :

$$
\begin{aligned}
& \mathrm{Cu}+2 \mathrm{OH}^{-} \rightleftharpoons \mathrm{CuO}+\mathrm{H}_{2} \mathrm{O}+2 \mathrm{e}^{-} \\
& \mathrm{Cu}+2 \mathrm{OH}^{-} \rightleftharpoons \mathrm{Cu}(\mathrm{OH})_{2}+2 \mathrm{e}^{-}
\end{aligned}
$$

There is some discrepancy in literature to claim the nature of the non-conductive $\mathrm{Cu}$ (II) species $(\mathrm{CuO}$ or $\left.\mathrm{Cu}(\mathrm{OH})_{2}\right) \cdot{ }^{29,30}$ Spectroscopy data derived for a similar system support the idea that a mixed oxide/hydroxide copper is formed during the anodic oxidation, the top layer being $\mathrm{Cu}(\mathrm{OH})_{2} \cdot{ }^{29}$ From energy dispersive X-ray spectroscopy results, ${ }^{4}$ we have already proposed that a layer of $\mathrm{CuO}$ is formed firstly during a potential scan to the positive direction. The formation of a passivating layer composed of $\mathrm{Cu}(\mathrm{OH})_{2}$ at more positive potentials depends on experimental conditions such as the rate of the electrodic process, temperature and the kinetics of the equilibrium involving the hydration process of $\mathrm{CuO}$ according to the following equation: ${ }^{24,27}$

$\mathrm{CuO}+\mathrm{H}_{2} \mathrm{O} \rightleftharpoons \mathrm{Cu}(\mathrm{OH})_{2}$

iii) At around $0.6 \mathrm{~V}$ : the further oxidation of $\mathrm{Cu}$ (II) to $\mathrm{Cu}(\mathrm{III})$ at more positive potentials has been proposed to explain this oxidative step. The frequency increase (reduction of the mass of the electrode) as indicated by $\mathrm{d} \Delta \mathrm{f} / \mathrm{dt}$ values (Figure 1) suggests that a soluble species is formed. However, RRDE studies ${ }^{1,3,4}$ have indicated that very low collection efficiency values are obtained at this potential region, suggesting that soluble and insoluble materials are simultaneously or competitively formed according to the following two possible equations:

$\mathrm{CuO}+2 \mathrm{OH}^{-} \rightleftharpoons \mathrm{CuO}_{2}^{-}+\mathrm{H}_{2} \mathrm{O}+\mathrm{e}^{-}$

$2 \mathrm{CuO}+2 \mathrm{OH}^{-} \rightleftharpoons \mathrm{Cu}_{2} \mathrm{O}_{3}+\mathrm{H}_{2} \mathrm{O}+2 \mathrm{e}^{-}$

In both equations $\mathrm{CuO}$ was considered to be the precursor of $\mathrm{Cu}(\mathrm{III})$, in agreement with results obtained from EDS results of various copper films grown at different potentials. ${ }^{4}$ Theoretical $\Delta \mathrm{m} / \mathrm{q}$ values related to the formation of $\mathrm{Cu}(\mathrm{III})$ (equations 6 and 7) were calculated as $-8.2 \times 10^{-4}$ and $0.8 \times 10^{-4} \mathrm{~g} \mathrm{C}^{-1}$, respectively. These values are significantly different from the one experimentally found $\left(-3.7 \times 10^{-4} \mathrm{~g} \mathrm{C}^{-1}\right)$, suggesting that both reactions described by equations 6 and 7 are likely responsible for the anodic process at around $0.6 \mathrm{~V}$. By using the theoretical $\Delta \mathrm{m} / \mathrm{q}$ values calculated from equations 6 and 7 and the experimental one, it was possible to conclude that both reactions contribute at the same extent, i.e., $50 \%$, to the anodic process at $0.6 \mathrm{~V}$. This supposition reinforces the conclusion from previous RRDE voltammetric experiments, ${ }^{3,4}$ where collection efficiency values measured at $0.6 \mathrm{~V}$ were lower than those obtained with $\mathrm{Fe}(\mathrm{CN})_{6}{ }^{4}$, an electroactive species whose oxidation product is stable and free-soluble in solution.

\section{Influence of the electrolyte concentration}

The influence of the concentration of hydroxide ions on the electrochemical profile was investigated by recording frequency shifts during potential scans at three different experimental conditions. Figure 4 shows that the frequency increase (mass diminution) at around $0 \mathrm{~V}$ is more pronounced when the $\mathrm{NaOH}$ concentration increases. This fact means that the formation of free-soluble copper ions at this potential region is facilitated at more alkaline solutions, as indicates the remarkable frequency increase observed in these curves. Finally, frequency shifts at the $0.6 \mathrm{~V}$ potential region are also more noticeable at $3 \mathrm{~mol} \mathrm{~L}^{-1} \mathrm{NaOH}$ electrolyte, a condition that favors the formation of free-soluble $\mathrm{Cu}$ (III) species.

\section{Time influence on the growth of the films}

In order to investigate the effect of the scan rate on the anodic oxidation of copper electrodes, experiments were performed at 5 and $50 \mathrm{mV} \mathrm{s}^{-1}$. Charge values measured under the anodic peaks shown in Figure 5 were 

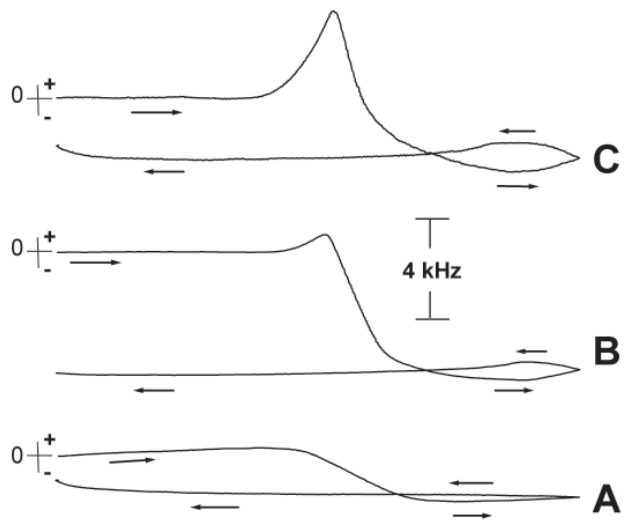

\begin{tabular}{ccccc}
\hline-0.8 & -0.4 & 0.0 & 0.4 & 0.8 \\
& & $E / V$ vs Ag/AgCl & &
\end{tabular}

Figure 4. Frequency plots for a copper electrodeposited quartz-crystal in $\mathrm{NaOH}$ solutions of different concentrations: 0.1 (A), 1 (B) and 3 (C) mol $\mathrm{L}^{-1}$. Scan rate: $50 \mathrm{mV} \mathrm{s}^{-1}$.

87 and $35 \mathrm{mC}$ for voltammetric experiments recorded at 5 and $50 \mathrm{mV} \mathrm{s}^{-1}$, respectively. This is in agreement with results presented in Figure 5, where frequency changes are noticed to be large at the lower scan rate. This would be expected as a consequence of the sudden change of the reaction path from formation of a soluble to an insoluble material, which is then continuously accumulated at the electrode interface.

Figure 5 also indicates a strong dependence of the electroreduction profile on the scan rate. For instance, at the higher scan rate $\left(50 \mathrm{mV} \mathrm{s}^{-1}\right)$ the electrode loses material at the end of the experiment, which suggests the existence of a time effect on the passivating layer growth. Hence, it is reasonable to suppose that the electroreduction profile depends on the history of the oxide layer and the equilibrium between its components, results in the literature ${ }^{30}$ reporting similar conclusions. This is reinforced by analyzing the frequency curve obtained at $5 \mathrm{mV} \mathrm{s}^{-1}$, which demonstrates that the initial frequency is restored at the quartz crystal at the end of the potential sweep. Hence, the very sluggish equilibrium between oxide and hydroxides layers is likely to be disturbed in experiments performed at relatively large time windows.

Some preliminary experiments were carried out to observe the effect of time on the frequency shifts at potentiostatic conditions. For instance, at $-0.2 \mathrm{~V}$ (Figure 6A) a small frequency increase accompanied by a sudden frequency decrease is observed, suggesting that as the local hydroxide ions concentration decreases to form $\mathrm{Cu}(\mathrm{OH})_{4}{ }_{4}^{2-}$, the formation of insoluble $\mathrm{Cu}$ (II) species is initiated. At more positive potentials, the effect of a more pronounced copper oxidation prevails and the formation of $\mathrm{CuO}$ and $\mathrm{Cu}(\mathrm{OH})_{2}$ occurs almost instantaneously (curves B, C and D). The amperometric profile shown in the insert of Figure 6 indicates that frequency shifts at this potential region occur essentially due to the electrode corrosion, no chemical transformation from $\mathrm{CuO}$ to $\mathrm{Cu}(\mathrm{OH})_{2}$ due to a hydration process (equation 5) being noticed during the open-circuit step. Curves E and $\mathrm{F}$, obtained at sufficiently positive potentials, confirm the formation of a passivating layer that restrains the electron transfer process.

\section{Anodic oxidation of ethanol at copper surfaces}

The mediation of the anodic oxidation of ethanol by a free-soluble $\mathrm{Cu}(\mathrm{III})$ species has already been postulated by voltammetry with $\mathrm{RRDE}^{3,4}$, as signals at the ring (due to the reduction of free-soluble $\mathrm{Cu}(\mathrm{III})$ electrogenerated at the disc) decrease as the concentration of ethanol increases. We have investigated this electrode process by monitoring frequency shifts during the anodic process in $1 \mathrm{~mol} \mathrm{~L}^{-1} \mathrm{NaOH}$ solutions before and after addition of ethanol ( 0.17 and $\left.0.85 \mathrm{~mol} \mathrm{~L}^{-1}\right)$. From voltammograms in Figure 7 it is possible to confirm the participation of a copper species in the electrode process involving the oxidation of ethanol, as a large anodic current enhancement associated with the disappearance of the cathodic signal (at $0.55 \mathrm{~V}$ in Figure 7A) is observed upon addition of ethanol to the $\mathrm{NaOH}$ solution.

The frequency shift measured from the beginning to the end of the potential scan increases and corresponds to a mass diminution of $16 \mu \mathrm{g} \mathrm{cm}^{-2}$ (measured at $0.1 \mathrm{~V}$

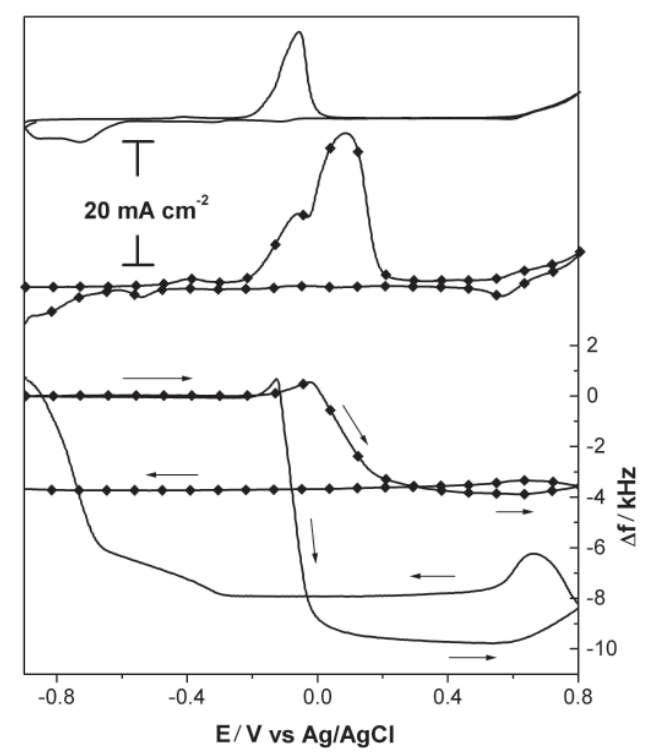

Figure 5. Cyclic voltammetry and $\Delta \mathrm{f} v s$ potential plots recorded with a copper electrodeposited quartz-crystal in a $1 \mathrm{~mol} \mathrm{~L}^{-1} \mathrm{NaOH}$ solution at 5 $\left(\right.$ ( ) and $50(-\bullet) \mathrm{mV} \mathrm{s}^{-1}$. 


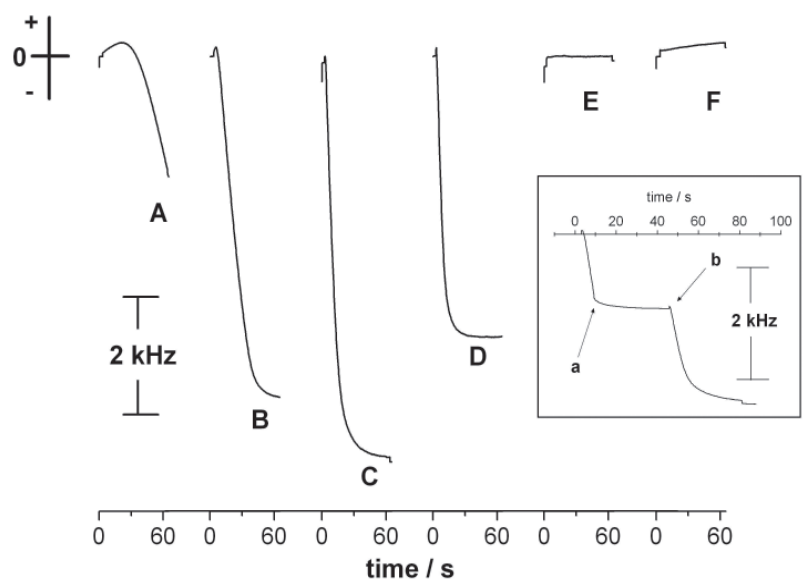

Figure 6. Frequency plots for amperometric studies in a $1 \mathrm{~mol} \mathrm{~L}^{-1} \mathrm{NaOH}$ solution with a copper electrodeposited quartz-crystal at different potentials: -0.20 (A), -0.15 (B), -0.10 (C), 0 (D), 0.10 (E) and $0.60 \mathrm{~V} v s \mathrm{Ag} / \mathrm{AgCl}$ (F). Insert shows an amperometric study performed at $-0.10 \mathrm{~V} v s \mathrm{Ag} / \mathrm{AgCl}$, an open-circuit condition being imposed between points $a$ and $b$.

as indicated in Figure 7A). When ethanol is added to the solution a mass diminution of $11 \mu \mathrm{g} \mathrm{cm}^{-2}$ is observed (Figure 7B). No significant frequency shift was observed at the more concentrated ethanol solution (Figure 7C). This is a clear indication that in the absence of ethanol (Figure 7A) the electrode suffers a dissolution process due to the formation of a free-soluble species $(\mathrm{Cu}(\mathrm{III}))$ in the forward scan. As the potential is reversed, the material not lost to the bulk solution may be reduced to an insoluble species and a partial mass recovery is observed. However, the chemical reduction of this copper oxidized species by ethanol occurs more efficiently if ethanol is added to the solution. Hence, the loss of $\mathrm{Cu}$ (III) to the solution is less effective and the frequency shifts is smaller in comparison to the experiment carried out in the absence of ethanol. Accordingly, curve C corresponds to a situation where the amount of ethanol in solution is so high that all material generated in the positive scan is reduced in the negative scan, i.e., the large concentration of ethanol ensures that the reaction layer is small compared to the diffusion layer.

Based on chromatographic and differential electrochemical mass spectrometry experiments, some authors have reported that the oxidation of ethanol at copper electrodes leads to the formation of acetate in a fourelectron process, acetaldehyde being a likely by product. ${ }^{2,31}$ Based on the conclusions above mentioned, a scheme for the electrocatalytic oxidation of ethanol at copper surfaces in alkaline medium has been proposed taking into consideration some suggestions on a similar process carried out at gold surfaces. ${ }^{32}$ The proposed mechanism involves the anodic oxidation of $\mathrm{CuO}$ in a first step (equation 7) followed by an O-transfer reaction from the electrochemically generated $\mathrm{CuO}_{2}^{-}$species to ethanol. Being an electrophile, this $\mathrm{Cu}(\mathrm{III})$ species promotes the loss of water from the ethanol molecule and leads to the formation of acetate and the redeposition of $\mathrm{CuO}$, this redeposition of an insoluble species being not reported in the literature. This proposed scheme showed below for the electrode process is in agreement with results in Figure 7C, where almost no mass change is observed during the voltammetric experiment owing to the regeneration of $\mathrm{CuO}$.

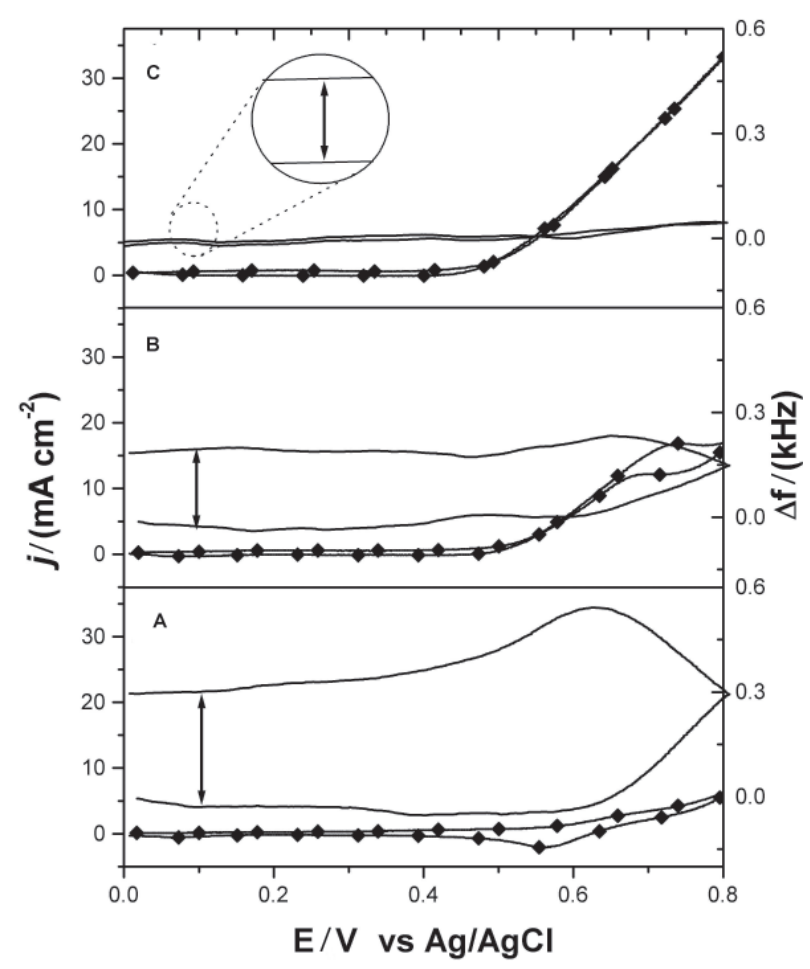

Figure 7 - Cyclic voltammetry (- -) and $\Delta \mathrm{f}(-)$ vs potential plots for a copper electrodeposited quartz-crystal in $1 \mathrm{~mol} \mathrm{~L}^{-1} \mathrm{NaOH}$ solution before (A) and after addition of ethanol to give the following final concentrations $\left(\mathrm{mol} \mathrm{L}^{-1}\right)=0.17(\mathrm{~B})$ and $0.85(\mathrm{C})$. Scan rate: $50 \mathrm{mV} \mathrm{s}^{-1}$.

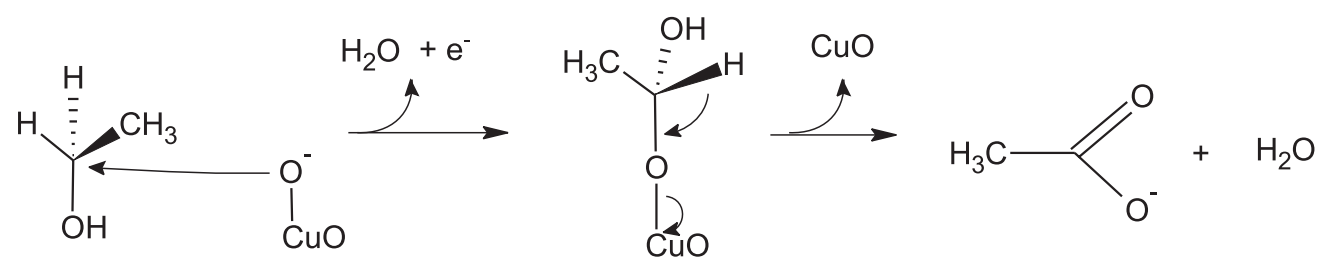

Scheme 1. 


\section{Conclusions}

By using an electrochemical quartz crystal microbalance we have demonstrated that $\mathrm{Cu}(\mathrm{I})$ and $\mathrm{Cu}(\mathrm{II})$ oxides and hydroxides have been formed at specific experimental conditions during the electrodic dissolution of copper electrodes in $\mathrm{NaOH}$ solutions. The first steps in the anodic process involve the formation of $\mathrm{Cu}_{2} \mathrm{O}$ and $\mathrm{Cu}(\mathrm{OH})_{4}^{2-}$, evidenced by EQCM data. Followed by the mass loss caused by the dissolution of copper and generation of a $\mathrm{Cu}$ (II) soluble species, a remarkable frequency decrease is observed as a consequence of the formation of $\mathrm{CuO}$ and $\mathrm{Cu}(\mathrm{OH})_{2}$ owing to the increase in the $\mathrm{Cu}$ (II) concentration at the vicinity of the electrode surface and the concurrent consumption of hydroxide ions. The composition of this film layer is dependent on experimental parameters such as hydroxide concentration, kinetics of the copper anodic oxidation and phase formation through nucleation and growth mechanisms. The generation of a soluble $\mathrm{Cu}(\mathrm{III})$ species from $\mathrm{CuO}$ at more positive potentials and its participation in the anodic oxidation of ethanol was definitely characterized by EQCM experiments, which also indicated that $\mathrm{CuO}$ can be entirely regenerated in the electrocatalytic process depending on the ethanol concentration.

\section{Acknowledgments}

Authors are grateful to FAPESP (Fundação de Amparo à Pesquisa do Estado de São Paulo and CNPq (Conselho Nacional de Desenvolvimento Científico e Tecnológico) for the financial support.

\section{References}

1. Miller, B.; J. Electrochem. Soc. 1969, 116, 1675.

2. Fleischman, M.; Korinek, K.; Plechter, D.; J. Chem. Soc., Perkin Trans. II 1972, 1396.

3. Paixão, T. R. L. C.; Corbo, D.; Bertotti, M.; Anal. Chim. Acta 2002, 472, 123.

4. Paixão, T. R. L. C.; Bertotti, M.; J. Electroanal. Chem. 2004, $571,101$.

5. Luo, M. Z.; Baldwin, R. P.; J. Electroanal. Chem. 1995, 387, 87.

6. Iwasita, T.; Rasch, B.; Cattano, E.; Vielstich, W.; Electrochim. Acta 1989, 34, 1073.

7. Beden, B.; Morin, M.-C.; Hahn, F.; Lamy, C.; J. Electroanal. Chem. 1987, 229, 353.

8. Callul, M.; Lopez, E.; Marce, R. M.; Olucha, J. C.; Borrull, F.; J. Chromatogr. 1992, 590, 215.

9. Ye, J.; Baldwin, R. P.; J. Chromatogr. 1994, 687, 141.
10. Quintino, M. D. M.; Corbo, D.; Bertotti, M.; Angnes, L.; Talanta 2002, 58, 943.

11. Corbo, D.; Bertotti, M.; Anal. Bioanal. Chem. 2002, 374, 416.

12. Paixão, T. R. L. C.; Matos, R.; Bertotti, M.; Electroanalysis 2003, 15, 1884.

13. Sánchez, M. P.; Barrera, M.; González, S.; Souto, R. M.; Salvarezza, R. C.; Arvia, A. J.; Electrochim. Acta 1990, 35, 1337.

14. Malvault, J. Y.; Lopitaux, J.; Delahaye, D.; Lenglet, M.; J. Appl. Electrochem. 1995, 25, 841.

15. Moll, D. V.; de Chialvo, M. R. G.; Salvarezza, R. C.; Arvia, A. J.; Electrochim. Acta 1985, 30, 1011.

16. Zhou, A.; He D.; Xie, N.; Xie, Q.; Nie, L.; Yao, S.; Electrochim. Acta 2000, 45, 3943.

17. Bertocci, U.; Electrochim. Acta 2004, 49, 1831.

18. Matsuoka, O.; Ono, S. S; Nozoye H.; Yamamoto, S.; Surf. Sci. 2003, 545,8 .

19. Varela, H.; Malta, M.; Torresi, R. M.; Quim. Nova 2000, 23, 664.

20. Sauerbrey, G.; Z. Phys. 1964, 178, 457.

21. Gabrielli, C.; Keddam, M.; Torresi, R.; J. Electrochem. Soc. 1991, 138, 2657.

22. Martin, S. J.; Granstaff, V. E.; Frye, G.C.; Anal. Chem. 1991, 63, 2272.

23. Buttry, D. A.; Ward, M. D.; Chem. Rev. 1993, 92, 1355.

24. Shoesmith, D. W.; Sunder, S.; Bailey, M. G.; Wallece, G. J.; Stanchell, F. W.; J. Electroanal. Chem. 1983, 143, 153.

25. de Chialvo, M. R. G.; Marchiano, S. L.; Arvia, A. J.; J. Appl. Electrochem. 1984, 14, 165.

26. Dong, S.; Xie, Y.; Cheng, G.; Electrochim. Acta 1992, 37, 17.

27. Pourbaix, M. In Lectures on Electrochemical Corrosion translated by J.A.S. Green, translantion edited by R.W. Staehle, $3^{\text {rd }}$ ed., expanded Imprenta Houston, NACE Internacional: NY, 1995 , pp. $110-143$.

28. Shoesmith, D. W.; Rummery, T. E.; Owen, D.; Lee, W.; J. Electrochem. Soc. 1976, 123, 790.

29. Pyun, C.-H.; Park, S. M.; J. Electrochem. Soc. 1986, 133, 2025.

30. Becerra, J. G.; Salvarezza, R. C.; Arvia, A.J.; Electrochim. Acta 1988, 33, 613 .

31. Pereira, M. G.; Jiménez, M. D.; Elizalde, M. P.; ManzoRobledo, A.; Alonso-Vante, N.; Electrochim. Acta 2004, 49, 3917.

32. Tremiliosi-Filho, G.; Gonzalez, E.R.; Motheo, A.J.; Belgsir, E.M.; Le'ger, J.-M.; Lamy, C., J. Electroanal. Chem. 1998, 444,31 .

Received: August 18, 2005

Published on the web: February 22, 2006

FAPESP helped in meeting the publication costs of this article. 